\title{
Second-generation antipsychotics and pregnancy complications
}

\author{
Maria Ellfolk ${ }^{1}$ - Maarit K. Leinonen ${ }^{2}$ - Mika Gissler ${ }^{2,3,4}$ - Anna-Maria Lahesmaa-Korpinen ${ }^{5} \cdot$ Leena Saastamoinen $^{6}$. \\ Marja-Leena Nurminen ${ }^{7,8} \cdot$ Heli Malm ${ }^{1,3,9,10}$
}

Received: 10 July 2019 / Accepted: 20 September 2019/Published online: 3 November 2019

(C) The Author(s) 2019

\begin{abstract}
Purpose To study if second-generation antipsychotic (S-GA) use during pregnancy is associated with an increased risk of pregnancy and neonatal complications.

Methods A population-based birth cohort study using national register data extracted from the "Drugs and Pregnancy" database in Finland, years 1996-2016. The sampling frame included 1,181,090 pregnant women and their singleton births. Women were categorized into three groups: exposed to S-GAs during pregnancy $(n=4225)$, exposed to first-generation antipsychotics (FGAs) during pregnancy $(n=1576$ ), and unexposed (no purchases of S-GAs or F-GAs during pregnancy, $n=21,125)$. Pregnancy outcomes in S-GA users were compared with those in the two comparison groups using multiple logistic regression models. Results Comparing S-GA users with unexposed ones, the risk was increased for gestational diabetes (adjusted odds ratio, OR 1.43 ; 95\% CI 1.25-1.65), cesarean section (OR 1.35; 95\% CI 1.18-1.53), being born large for gestational age (LGA) (OR 1.57; 95\% CI 1.14-2.16), and preterm birth (OR 1.29; 95\% CI 1.03-1.62). The risk for these outcomes increased further with continuous S-GA use. Infants in the S-GA group were also more likely to suffer from neonatal complications. Comparing SGA users with the F-GA group, the risk of cesarean section and LGA was higher (OR 1.25, 95\% CI 1.03-1.51; and OR 1.89, 95\% CI 1.20-2.99, respectively). Neonatal complications did not differ between the S-GA and F-GA groups.

Conclusions Prenatal exposure to S-GAs is associated with an increased risk of pregnancy complications related to impaired glucose metabolism. Neonatal problems are common and occur similarly in S-GA and F-GA users.
\end{abstract}

Keywords Second-generation antipsychotics $\cdot$ Pregnancy $\cdot$ Pregnancy complications $\cdot$ Neonatal complications

Electronic supplementary material The online version of this article (https://doi.org/10.1007/s00228-019-02769-z) contains supplementary material, which is available to authorized users.

Heli Malm

heli.malm@hus.fi

1 Teratology Information, Department of Emergency Medicine Services, Helsinki University and Helsinki University Hospital, Tukholmankatu 17, 00029 Helsinki, Finland

2 Information Services Department, Unit of Statistics and Registers, National Institute for Health and Welfare, PL 30, 00271 Helsinki, Finland

3 Research Centre for Child Psychiatry, University of Turku, Itäinen Pitkäkatu 1, 20520 Turku, Finland

4 Department of Neurobiology, Care Sciences and Society, Karolinska Institute, SE-141 83 Huddinge, Sweden

5 Present address: Hospital \& Health Care, Terveystalo, Jaakonkatu 3 B, 00100 Helsinki, Finland
6 Research Unit, The Social Insurance Institution, Nordenskiöldinkatu 12, 00250 Helsinki, Finland

7 Finnish Medicines Agency FIMEA, Mannerheimintie 103b, 00280 Helsinki, Finland

8 Present address: Swedish Medical Products Agency, P.O. Box 26, SE-751 03 Uppsala, Sweden

9 Department of Clinical Pharmacology, Helsinki University and Helsinki University Hospital, PL 20 (Tukholmankatu 8 C), 00014 Helsinki, Finland

10 Individualized Drug Therapy Research Program, Faculty of Medicine, University of Helsinki, PL 20 (Tukholmankatu 8 C), 00014 Helsinki, Finland 


\section{Introduction}

Use of the second-generation antipsychotics (S-GAs) has increased during the last decades. This tendency is evident not only on population level but also within the pregnant population. In the USA, the prevalence of use of S-GAs during pregnancy increased from 0.4 to $1.3 \%$ in 2001-2010, while the use of first-generation antipsychotics (F-GAs) remained stable at around $0.1 \%$ [1]. The increased use of S-GAs may be related to the argued, but not uniformly proven, better tolerability or a more favorable side-effect profile when compared with that of F-GAs [2]. Off-label use, including use as hypnotics and sedatives, may also play a role. There are no published data on use of antipsychotics during pregnancy in Finland.

Several S-GAs - contrary to FGAs - have minor effect on prolactin secretion [3] and pregnancies may occur more easily during treatment. Use of S-GAs may predispose to hyperglycemia [3,4], and maternal gestational diabetes increases the risk of several pregnancy complications including being born large for gestational age (LGA). While some previous studies have reported an increased risk of gestational diabetes [5-7] or LGA $[8,9]$ associated with S-GA use, not all studies have confirmed these associations [10-13]. Use of S-GAs during pregnancy has also been associated with increased risk of being born small for gestational age (SGA) [10], low birth weight [14], and preterm birth [9, 10, 12, 15], but results have been conflicting $[5,13]$. Antipsychotic drugs can further give rise to neonatal symptoms reflected in poor Apgar score or need for treatment in the neonatal care unit. Even though SGA treatment is suspected to increase the risk of pregnancy complications, changing effective medication is rarely possible as maternal well-being is a prerequisite for a favorable pregnancy outcome. Because of the increasing use of S-GAs among pregnant women and conflicting data on their safety, we investigated the association between S-GA use during pregnancy and pregnancy and neonatal complications using nationwide register data.

\section{Methods}

This is a population-based birth cohort study using national register data extracted from the existing Drugs and Pregnancy database, established by the National Institute for Health and Welfare (THL), the Social Insurance Institution of Finland (Kela), and the Finnish Medicines Agency (FIMEA) [16]. The objective of the database is continuous surveillance of drug safety during pregnancy by using the Medical Birth Register, the Abortion Register, the National Register of Congenital Malformations, and the Prescription Register, including also the Special Refund Entitlement Register. Data from these registers have been linked by the personal identification number assigned to all citizens and permanent residents in Finland. Data from births and terminations of pregnancy, and prescription drug purchases have been collected since 1 Jan. 1996. The beginning of pregnancy has been calculated from the best clinical estimation of gestational age at birth, primarily based on ultrasound. Pregnancy trimesters are divided into first (until 84 days' gestation), second (days 85-182), and third (days 183 until birth).

The Medical Birth Register (MBR) maintained since 1987 by THL is a nationwide register collecting data on maternal demographic characteristics, medical and reproductive history, smoking, diagnoses during pregnancy and delivery, and neonatal outcome data up to 6 days' age. Data in the MBR includes all live births and stillbirths with gestational age of 22 weeks or more or birth weight of $500 \mathrm{~g}$ or more, and the completeness of births is close to $100 \%$ [17-19]. The definitions and variables included in this registry are based on established international concepts and use the 10th version of the WHO International Classification of Diseases (ICD) since 1996 (children) and 2004 (mothers).

The Finnish Prescription Registry (Kela) contains data on reimbursed prescription drug purchases [20]. Prescriptiononly medicines deemed necessary for the treatment of an illness are reimbursed under the national social insurance which covers all permanent residents in Finland. Drug purchases are reimbursed concomitantly upon purchase at pharmacies, and drugs are supplied to the patient for a maximum of 3 months at a time. Data in the register include the date of the purchase and the International Anatomical-Therapeutic-Chemical (ATC) classification code indicating the generic name of the drug (https://www.who.int/classifications/atcddd/en/). Over-thecounter drugs or medications given to institutionalized persons are not included in the register. The Kela also maintains the Special Refund Entitlement Register since 1964 with data on patients who are entitled for higher reimbursement for chronic illnesses requiring continuous drug treatment.

\section{Definition of exposed and unexposed cohorts}

This study frame included 1,181,090 pregnancies ending in singleton birth in Finland between 1 Jan. 1996 and 31 Dec. 2016 recorded in the Drugs and Pregnancy database (Fig. 1). Exposed to S-GAs: women who purchased S-GAs (olanzapine, quetiapine, risperidone, aripiprazole, clozapine, ziprasidone, sertindole, or asenapine; Supplementary Table S1) at any time during pregnancy or 1 month before pregnancy $(n=4225)$. Continuous use of S-GAs: women who purchased S-GAs in at least two trimesters $(n=2135)$. Unexposed: pregnant women who had no purchases of S-GAs or F-GAs during the period of 1 month prior to pregnancy until the end of pregnancy. Controls in this group were matched for year of birth of child ( \pm 1 month) and were randomly selected as five controls for one exposed $(5: 1)(n=21,125)$. Exposed to F-GAs: women who purchased F-GAs (Supplementary 
Fig. 1 Flow chart of the exposure and outcome information used in the study

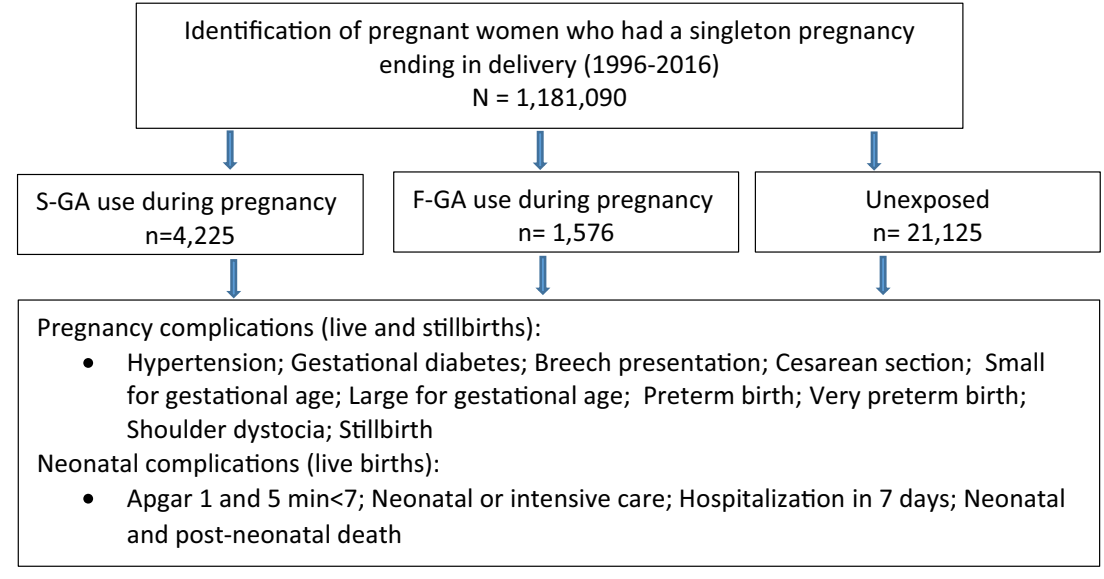

Table 1) but did not purchase S-GAs during the same period ( $n$ $=2126$ ). This comparison group was included to control for maternal psychiatric illness. Pregnancies that were only exposed to prochlorperazine ( $n=550$ ) were excluded because it is mostly used for morning sickness, leaving 1576 women in the F-GA group for analyses. Continuous use of F-GAs: women who purchased F-GAs in at least two trimesters $(n=722)$.

\section{Maternal characteristics and covariates}

Covariates included maternal demographic, social and medical characteristics, and use of other drugs, categorized as shown in Table 1. Data on prepregnancy BMI were available only beginning from 2004 and for all women from September 2005. Alcohol use is not routinely collected in the MBR and could therefore not be included in analyses.

\section{Outcome variables}

The outcomes related to pregnancy and delivery included hypertension of pregnancy (ICD-10 diagnoses O10, O11, O16 or MBR hypertension record), gestational diabetes (ICD-10 diagnoses O24.4 and O24.9, pathological glucose tolerance test or MBR diabetes record with no information on pregestational diabetes), breech presentation, cesarean section, small for gestational age (SGA, birth weight of more than two standard deviations less than the sex- and length-of-gestation-specific national standards), large for gestational age (LGA, birth weight of more than two standard deviations more than the sex- and length-of-gestation-specific national standards) [21], categorically defined late preterm (32-36 gestational weeks) and very preterm birth ( $<32$ weeks), shoulder dystocia, and stillbirth. Neonatal outcomes included 1- and 5-min Apgar scores $<7$, monitoring in neonatal care or neonatal intensive care unit (NCU), hospitalization at 7 days age, neonatal death, and post-neonatal death (Fig. 1).

\section{Statistical analyses}

All data in the Drugs and Pregnancy database are pseudonymized. The prevalence of specific outcomes was compared between the S-GA group, the unexposed group, and the F-GA group. Univariate analyses were used to study demographic differences between the study cohorts, and the logistic regression to assess the association between S-GA use during pregnancy and pregnancy and perinatal outcomes.

The crude model included adjustment for year of delivery. For the adjusted analyses, clinically relevant and plausible covariates were first tested for association with the three-class exposure status. When associated with exposure at significance level $p<0.1$, the covariate was further tested separately for association with each outcome. For each of the 16 outcomes, we included in the logistic regression model covariates which were associated with exposure and outcome at $p<0.1$ as potential confounders (Supplementary Table S2). We also analyzed third trimester use separately for neonatal outcomes. All analyses were performed in SAS (SAS 12.1, NC, USA).

The utilization of sensitive health register data for scientific research and the data linkages in the "Drugs and Pregnancy" project have been approved by the register administrators and the national data protection authority. The study protocol was approved by the Institutional Review Board at the National Institute for Health and Welfare (THL). Since the study subjects are not contacted, according to the Finnish legislation, informed consent is not required for large register studies. The study was registered in The European Network of Centres for Pharmacoepidemiology and Pharmacovigilance (ENCePP) register before data collection started (EUPAS4799). The study has been granted the ENCePP seal, following the ENCePP principles of standards, transparency, and independence of good pharmacoepidemiology practice throughout the research process (www.encepp.eu). 
Table 1 Maternal characteristics. Mothers with a singleton birth $(N=26,926)$

\begin{tabular}{|c|c|c|c|c|c|c|c|}
\hline & \multicolumn{2}{|c|}{$\begin{array}{l}\text { Second-generation } \\
\text { antipsychotics (S-GAs) }\end{array}$} & \multicolumn{2}{|c|}{$\begin{array}{l}\text { First-generation } \\
\text { antipsychotics (F-GAs) }\end{array}$} & \multicolumn{2}{|c|}{ Unexposed } & \multirow{2}{*}{$\begin{array}{l}\text { Covariate associated } \\
\text { with exposure } \\
p \text { value }\end{array}$} \\
\hline & $n$ & $\%$ & $n$ & $\%$ & $n$ & $\%$ & \\
\hline & 4225 & 100.0 & 1576 & 100.0 & 21,125 & 100.0 & \\
\hline Age at delivery & & & & & & & $<0.0001$ \\
\hline $20-34$ & 3113 & 73.7 & 1020 & 64.7 & 16,539 & 78.3 & \\
\hline$<20$ or $\geq 35$ & 1112 & 26.3 & 556 & 35.3 & 4586 & 21.7 & \\
\hline Parity & & & & & & & $<0.0001$ \\
\hline No previous deliveries & 2176 & 51.5 & 637 & 40.4 & 8803 & 41.7 & \\
\hline 1 or more previous deliveries & 2049 & 48.5 & 939 & 59.6 & 12,322 & 58.3 & \\
\hline Prepregnancy BMI mean, $(\mathrm{SD})^{\mathrm{a}}$ & 26.3 & 6.1 & 26.2 & 5.8 & 24.5 & 5.0 & $<0.0001$ \\
\hline$<18.5$ & 155 & 3.7 & 13 & 0.8 & 714 & 3.4 & \\
\hline $18.5-24.9$ & 1869 & 44.2 & 336 & 21.3 & 12,240 & 57.9 & \\
\hline$\geq 25.0$ & 1923 & 45.5 & 321 & 20.4 & 6918 & 32.8 & \\
\hline Unknown & 278 & 6.6 & 906 & 57.5 & 1253 & 5.9 & \\
\hline Marital status & & & & & & & $<0.0001$ \\
\hline Married/co-habiting & 3154 & 74.7 & 1250 & 79.3 & 18,862 & 89.3 & \\
\hline Single & 704 & 16.7 & 195 & 12.4 & 1101 & 5.2 & \\
\hline Unknown & 367 & 8.7 & 131 & 8.3 & 1162 & 5.5 & \\
\hline Smoking & & & & & & & $<0.0001$ \\
\hline No & 2299 & 54.4 & 923 & 58.6 & 17,491 & 82.8 & \\
\hline Yes & 1790 & 42.4 & 598 & 37.9 & 3115 & 14.8 & \\
\hline Unknown & 136 & 3.2 & 55 & 3.5 & 519 & 2.5 & \\
\hline Socioeconomic status & & & & & & & $<0.0001$ \\
\hline Upper white collar & 299 & 7.1 & 145 & 9.2 & 2724 & 12.9 & \\
\hline Lower white collar & 767 & 18.2 & 504 & 32.0 & 5434 & 25.7 & \\
\hline Blue collar & 454 & 10.8 & 266 & 16.9 & 2126 & 10.1 & \\
\hline Other & 876 & 20.7 & 384 & 24.4 & 2751 & 13.0 & \\
\hline Unknown & 1829 & 43.3 & 277 & 17.6 & 8090 & 38.3 & \\
\hline Exposure to other psychiatric drugs ${ }^{b}$ & 2818 & 66.7 & 936 & 59.4 & 931 & 4.4 & $<0.0001$ \\
\hline Exposure to known teratogens & 672 & 15.9 & 172 & 10.9 & 215 & 1.0 & $<0.0001$ \\
\hline \multicolumn{8}{|l|}{ Maternal illness } \\
\hline Psychotic and other severe mental disorders & 1661 & 39.3 & 625 & 39.7 & 60 & 0.2 & $<0.0001$ \\
\hline Pregestational diabetes ${ }^{c}$ & 83 & 2.0 & 16 & 1.0 & 171 & 0.8 & $<0.0001$ \\
\hline Other chronic diseases & 240 & 5.7 & 78 & 5.0 & 1355 & 6.4 & 0.0198 \\
\hline
\end{tabular}

${ }^{\text {a }}$ Data available from 2004

${ }^{\mathrm{b}}$ Other psychiatric drugs, including anxiolytics (ATC codes N05B), hypnotics and sedatives (N05C), antidepressants (N06A), psychostimulants (N06B), antidepressant-combination preparations (N06C), drugs used in addictive disorders (N07B)

${ }^{\mathrm{c}}$ Diagnoses (ICD 10) E10-E11 and O24.0-O24.1 or medical reimbursement for diabetes, obtained from the Special reimbursement register (Social Insurance Institution, Kela)

\section{Results}

Overall, the prevalence of any antipsychotic use in 1,181,090 singleton births was $0.5 \%$ during pregnancy or 30 days before it. S-GAs have basically replaced the use of F-GAs among pregnant women during the last 20 years (Fig. 2). A total of $4225(0.4 \%)$ women purchased S-GAs during pregnancy or 30 days before pregnancy, and $2135(0.2 \%)$ had prescription fills in at least two trimesters. S-GA and F-GA users were two or three times more frequently smokers than women not using antipsychotics. Overweight was also more prevalent in S-GA users than in unexposed women ( $45.5 \%$ vs. $32.8 \%)$. Maternal characteristics of the three study groups are presented in Table 1.

Pregnancy and delivery diagnoses by exposure status are presented in Table 2. Compared with that in the unexposed 
Fig. 2 Time trends in secondgeneration antipsychotic (S-GA) and first-generation antipsychotic (F-GA) purchases in pregnant women in Finland, years 1996 2016
- F-GA S-GA

1.2

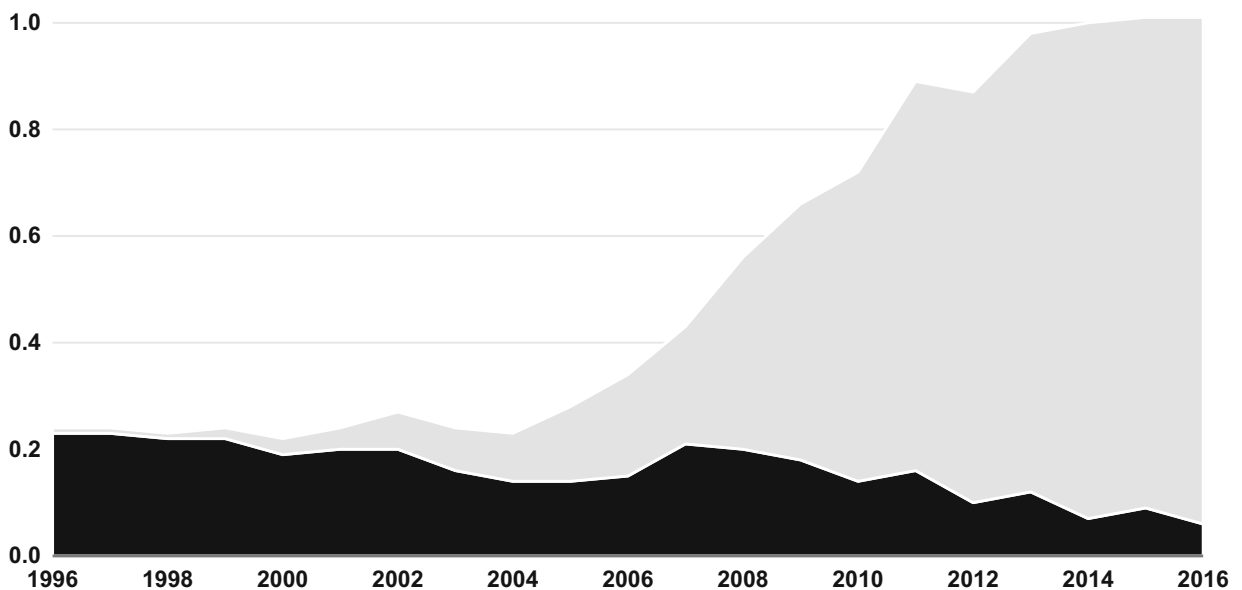

group, the risk of several pregnancy complications was increased in the S-GA group. The risk of gestational diabetes, cesarean section, LGA, and preterm birth remained clearly higher in the S-GA group also after adjustment (Table 2). Compared with that in the F-GA group, the risk of gestational diabetes was not increased, while the risk of cesarean section was $25 \%$ higher and LGA was close to twice as high in the SGA group (adjusted OR 1.89; 95\% CI 1.20-2.99) (Table 2). Of the most commonly used S-GAs, the prevalence of gestational diabetes ranged from $18.6 \%$ among risperidone users to $32.8 \%$ among clozapine users (Table 3 ).

Infants in the S-GA group were more likely to receive poor Apgar scores, to need treatment in neonatal care or intensive care unit and to be hospitalized at 7 days when compared with the unexposed group (Table 4). The risk of neonatal complications did not differ between the S-GA and F-GA groups (Table 4).

Restricting analyses to women with continuous use of SGAs, the risk of gestational diabetes, cesarean section, LGA, and preterm birth increased further when compared with those in the unexposed group, while the risk of very preterm birth was lower (Table 5). Compared with the continuous use F-GA group, the risk of breech birth in the S-GA users was 2.7-fold, and the risk of LGA was 2.3-fold. This increased risk of cesarean section did not remain statistically significant after adjustment. Regardless of the increased risk of LGA, the risk of shoulder dystocia in S-GA pregnancies was not increased but the numbers were small (Table 5). Restricting analyses to third trimester purchases, the risk of receiving low Apgar scores, the risk of treatment in neonatal care or intensive care unit, and the risk of hospitalization at 7 days were further increased in the S-GA group when compared with those in the unexposed group. No differences in the risk of neonatal complications were observed between the S-GA and F-GA groups (Supplementary Table 3).

\section{Discussion}

In this population-based study, S-GA use during pregnancy was associated with an increased risk of pregnancy complications, including gestational diabetes, cesarean section, LGA, and preterm birth when compared with the unexposed group. The risk for several neonatal complications was also increased. Compared with F-GAs, the risk for cesarean section was increased by $25 \%$, and the risk for LGA was nearly 2-fold, while the risk of neonatal complications did not differ between these groups.

Previously published studies investigating the safety of SGA use during pregnancy have been based on population registries [5, 11, 22], electronic health records [12, 13], insurance data [23], hospital registers [24, 25], and data from pharmacovigilance and teratology information centers, the latter typically based on prospectively collected exposure data [8-10, 26]. A few studies have considered mothers' psychiatric illness using untreated disease controls, and few studies have compared different types of antipsychotics [11, 12, 26]. Because of different data sources and research methods, the results have often been conflicting and are difficult to compare. However, similarities in certain maternal characteristics have been observed across the studies. Mothers using antipsychotics tend to smoke more frequently, have a higher prepregnancy BMI, and have lower socioeconomic status (SES) than non-users [27, 28]. Smoking, obesity, and lower SES were associated with antipsychotic use also in our material. 
Table 2 Pregnancy complications among second-generation antipsychotic (S-GA) users, first-generation antipsychotic (F-GA) users, and unexposed mothers

\begin{tabular}{|c|c|c|c|c|c|c|c|c|c|c|c|c|c|c|}
\hline \multirow[t]{2}{*}{ Outcome } & \multicolumn{2}{|c|}{$\begin{array}{l}\text { S-GA } n= \\
4225\end{array}$} & \multicolumn{2}{|c|}{$\begin{array}{l}\text { F-GA } n= \\
1576\end{array}$} & \multicolumn{2}{|c|}{$\begin{array}{l}\text { Unexposed } \\
n=21,125\end{array}$} & \multicolumn{4}{|c|}{ S-GA vs. unexposed } & \multicolumn{4}{|c|}{ S-GA vs. F-GA } \\
\hline & $n$ & $\%$ & $n$ & $\%$ & $n$ & $\%$ & $\begin{array}{l}\text { Crude } \\
\text { OR }\end{array}$ & $95 \% \mathrm{CI}$ & $\begin{array}{l}\text { Adjusted } \\
\text { OR }\end{array}$ & $95 \% \mathrm{CI}$ & $\begin{array}{l}\text { Crude } \\
\text { OR }\end{array}$ & $95 \% \mathrm{CI}$ & $\begin{array}{l}\text { Adjusted } \\
\text { OR }\end{array}$ & $95 \% \mathrm{CI}$ \\
\hline Hypertension & 122 & 3.0 & 69 & 9.2 & 371 & 1.8 & 1.67 & $1.36-2.07$ & 0.98 & $0.65-1.47$ & 1.07 & $0.74-1.55$ & 0.90 & $0.59-1.38$ \\
\hline Gestational diabetes & 1051 & 24.9 & 191 & 12.1 & 3047 & 14.4 & 1.98 & $1.83-2.15$ & 1.43 & $1.25-1.65$ & 1.07 & $0.87-1.31$ & 0.97 & $0.78-1.20$ \\
\hline Breech birth & 122 & 2.9 & 29 & 1.8 & 527 & 2.5 & 1.16 & $0.95-1.42$ & 1.10 & $0.90-1.34$ & 1.92 & $1.13-3.27$ & 1.70 & $1.00-2.89$ \\
\hline Cesarean section & 1057 & 25.0 & 336 & 21.3 & 3251 & 15.4 & 1.83 & $1.70-1.99$ & 1.35 & $1.18-1.53$ & 1.29 & $1.07-1.55$ & 1.25 & $1.03-1.51$ \\
\hline $\begin{array}{l}\text { Small for } \\
\text { gestational age }\end{array}$ & 223 & 5.3 & 96 & 6.1 & 779 & 3.7 & 1.46 & $1.25-1.70$ & 1.02 & $0.80-1.30$ & 0.91 & $0.65-1.26$ & 0.82 & $0.58-1.16$ \\
\hline $\begin{array}{l}\text { Large for } \\
\text { gestational age }\end{array}$ & 159 & 3.8 & 46 & 2.9 & 455 & 2.2 & 1.78 & $1.48-2.14$ & 1.57 & $1.14-2.16$ & 1.76 & $1.13-2.75$ & 1.89 & $1.20-2.99$ \\
\hline $\begin{array}{l}\text { Preterm birth } \\
\text { 32-36 weeks }\end{array}$ & 295 & 7.0 & 97 & 6.2 & 794 & 3.8 & 1.92 & $1.68-2.21$ & 1.29 & $1.03-1.62$ & 0.92 & $0.68-1.25$ & 0.87 & $0.63-1.20$ \\
\hline $\begin{array}{l}\text { Very preterm birth } \\
<32 \text { weeks }\end{array}$ & 50 & 1.2 & 37 & 2.4 & 170 & 0.8 & 1.48 & $1.08-2.03$ & 0.78 & $0.45-1.32$ & 0.87 & $0.48-1.60$ & 0.78 & $0.41-1.47$ \\
\hline Shoulder dystocia $^{\mathrm{a}}$ & 13 & 0.3 & 3 & 0.2 & 52 & 0.3 & 1.25 & $0.68-2.30$ & 1.16 & $0.62-2.14$ & 0.57 & $0.13-2.40$ & 0.58 & $0.14-2.41$ \\
\hline Stillbirth $^{\mathrm{a}}$ & 21 & 0.5 & 12 & 0.8 & 56 & 0.3 & 1.88 & $1.14-3.11$ & 0.56 & $0.23-1.32$ & 0.59 & $0.23-1.52$ & 0.57 & $0.20-1.61$ \\
\hline
\end{tabular}

Missing data on outcome excluded from analyses: hypertension 6.3\%, SGA, LGA and cesarean section $<0.1 \%$ of pregnancies

$O R$, odds ratio; $C I$, confidence interval; Crude OR, adjusted for year of delivery; Adjusted OR, adjusted for year of delivery and covariates associated with exposure and outcome at $p<0.1$ as given in Supplementary Table 2

${ }^{a}$ Changes in adjusting variables due to small numbers. Shoulder dystocia: BMI and socioeconomic status categories reduced; stillbirth: socioeconomic status categories reduced

Use of S-GAs can affect normal glucose metabolism and induce weight gain by inhibiting the insulin signaling pathway which leads to insulin resistance and increased insulin production, or by direct damage to pancreatic beta cells [29]. During pregnancy, high maternal blood glucose results in increased fetal insulin production. Insulin is an anabolic hormone and promotes fetal growth. Apart from genetically determined

Table 3 Number of pregnancies with second-generation antipsychotic (S-GA) purchases and gestational diabetes recorded during pregnancy by drug

\begin{tabular}{llll}
\hline S-GA & \multirow{2}{*}{ Exposed pregnancies } & \multicolumn{2}{c}{ Gestational diabetes } \\
\cline { 3 - 4 } & $n$ & $n$ & $\%$ \\
\hline Quetiapine & 3244 & 799 & 24.6 \\
Olanzapine & 573 & 170 & 29.7 \\
Risperidone & 317 & 59 & 18.6 \\
Aripiprazole & 220 & 71 & 32.3 \\
Clozapine & 119 & 39 & 32.8 \\
Ziprasidone & 17 & 1 & 5.9 \\
Sertindole & 7 & 3 & 42.9 \\
Asenapine & 2 & 1 & 50.0 \\
\hline
\end{tabular}

There were no drug purchases for the following S-GAs: paliperidone, lurasidone, sultopride, remoxipride, amisulpride, levosulpiride, mosapramine, zotepine, paliperidone, iloperidone, cariprazine, and brexpiprazole characteristics, maternal diabetes and high prepregnancy BMI are major risk factors for being born LGA. Previous research has shown conflicting results: increased risk of gestational diabetes was not observed in studies based on prospective interviews [28], electronic health records [12], and health administrative databases [13], while a recent study based on Medicaid data observed an increased risk of gestational diabetes in women using olanzapine or quetiapine [1]. Two previous studies with prospectively collected exposure data reported an increased risk of LGA associated with S-GA use [8,9], but the numbers of exposed were too small for meaningful analysis. Contrary to these, the anticipated increased risk of being born LGA was not observed in a Swedish population-based cohort study after prenatal exposure to olanzapine or clozapine, the two most diabetogenic S-GAs [5]. We observed a $43 \%$ increase of gestational diabetes and a 57\% increased risk of LGA in S-GA users compared with the unexposed ones, and these risks increased further with continuous use of S-GAs. Compared with that in the F-GA group, the risk of gestational diabetes was not increased, while the risk of LGA was increased by nearly $90 \%$. However, only insulin-treated gestational diabetes was recorded in the MBR before 2004. Recording of glucose intolerance test and gestational diabetes diagnoses started only in 2004 . Similarly, recording of maternal height and weight —used in calculating BMI — did not start until 2004. This coincides with the change in pattern of S-GA and F-GA use (Fig. 2) and is reflected in the large number (nearly $60 \%$ ) of missing data of 
Table 4 Neonatal outcomes among second generation antipsychotic (S-GA) users, first-generation antipsychotic (F-GA) users, and unexposed mothers

\begin{tabular}{|c|c|c|c|c|c|c|c|c|c|c|c|c|c|c|}
\hline \multirow[t]{2}{*}{ Outcome } & \multicolumn{2}{|c|}{$\begin{array}{l}\text { S-GA, } n \\
=4204\end{array}$} & \multicolumn{2}{|c|}{$\begin{array}{l}\text { F-GA, } n \\
=1564\end{array}$} & \multicolumn{2}{|c|}{$\begin{array}{l}\text { Unexposed, } \\
n=21,069\end{array}$} & \multicolumn{4}{|c|}{ S-GA $v s$. unexposed } & \multicolumn{4}{|c|}{ S-GA $v s$. F-GA } \\
\hline & $n$ & $\%$ & $n$ & $\%$ & $n$ & $\%$ & $\begin{array}{l}\text { Crude } \\
\text { OR }\end{array}$ & $95 \% \mathrm{CI}$ & $\begin{array}{l}\text { Adjusted } \\
\text { OR }\end{array}$ & $95 \% \mathrm{CI}$ & $\begin{array}{l}\text { Crude } \\
\text { OR }\end{array}$ & $95 \% \mathrm{CI}$ & $\begin{array}{l}\text { Adjusted } \\
\text { OR }\end{array}$ & $95 \% \mathrm{CI}$ \\
\hline Apgar $1 \min 0-6$ & 409 & 9.8 & 142 & 9.1 & 1160 & 5.5 & 1.85 & $1.65-2.08$ & 1.40 & $1.15-1.70$ & 1.00 & $0.77-1.30$ & 0.99 & $0.75-1.29$ \\
\hline Apgar $5 \min 0-6$ & 212 & 6.0 & 38 & 6.3 & 399 & 2.3 & 2.75 & $2.32-3.26$ & 1.82 & $1.38-2.39$ & 0.86 & $0.59-1.27$ & 0.81 & $0.55-1.20$ \\
\hline $\mathrm{NCU}$ & 990 & 23.6 & 335 & 21.4 & 2134 & 10.1 & 2.73 & $2.51-2.97$ & 1.46 & $1.27-1.68$ & 1.12 & $0.93-1.35$ & 0.93 & $0.77-1.13$ \\
\hline $\begin{array}{l}\text { Hospitalization at } \\
7 \text { days }\end{array}$ & 602 & 14.3 & 233 & 14.9 & 1121 & 5.3 & 2.98 & $2.68-3.31$ & 1.52 & $1.27-1.82$ & 1.26 & $1.01-1.57$ & 1.02 & $0.81-1.28$ \\
\hline $\begin{array}{l}\text { Early neonatal death } \\
\qquad(0-6 \text { days })^{\mathrm{a}}\end{array}$ & 4 & 0.1 & 7 & 0.5 & 19 & 0.1 & 1.05 & $0.36-3.10$ & 0.87 & $0.20-3.75$ & 0.27 & $0.05-1.37$ & 0.28 & $0.05-1.44$ \\
\hline $\begin{array}{l}\text { Post-early neonatal } \\
\text { death (7-364 days) or } \\
\text { other infant deaths } \\
\text { (7-364 days) }\end{array}$ & 19 & 0.5 & 15 & 1.0 & 41 & 0.2 & 2.33 & $1.35-4.01$ & 1.43 & $0.58-3.56$ & 0.49 & $0.20-1.22$ & 0.43 & $0.17-1.08$ \\
\hline
\end{tabular}

Missing data on outcome excluded from analyses: Apgar $1 \mathrm{~min} 0.3 \%$, Apgar $5 \mathrm{~min} 18.4 \%$, hospitalization in 7 days $0.2 \%$ of pregnancies

$N C U$, neonatal care or intensive care unit; $O R$, odds ratio; $C I$, confidence interval; Crude OR, odds ratio adjusted for year of delivery; Adjusted OR, odds ratio adjusted for year of delivery and covariates associated with exposure and outcomes at $p<0.1$ as given in Supplementary Table 2

${ }^{a}$ Changes in adjusting variables due to small numbers: BMI categories reduced

BMI in the F-GA group. Thus, completeness of pregestational and gestational diabetes diagnoses in our material substantially improves over time, and comparing the risks of gestational diabetes and LGA between S-GA and F-GA users is therefore of limited value. However, the S-GAs are known to pass the placenta [30] and a direct effect on fetal insulin secretion is therefore also possible. It could be hypothesized that even in the absence of maternal hyperglycemia, fetal exposure to S-GAs could cause inhibition of insulin signaling, followed by insulin resistance and increased insulin secretion in the fetus.

Table 5 Pregnancy complications among second-generation antipsychotic (S-GA) users, first-generation antipsychotic (F-GA) users, and unexposed mothers during at least two trimesters

\begin{tabular}{|c|c|c|c|c|c|c|c|c|c|c|c|c|c|c|}
\hline \multirow[t]{2}{*}{ Outcome } & \multicolumn{2}{|c|}{$\begin{array}{l}\text { S-GA, } n \\
=2135\end{array}$} & \multicolumn{2}{|c|}{$\begin{array}{l}\text { F-GA, } n \\
=722\end{array}$} & \multicolumn{2}{|c|}{$\begin{array}{l}\text { Unexposed, } \\
n=21,125\end{array}$} & \multicolumn{4}{|c|}{ S-GA vs. unexposed } & \multicolumn{4}{|c|}{ S-GA vs. F-GA } \\
\hline & $n$ & $\%$ & $n$ & $\%$ & $n$ & $\%$ & $\begin{array}{l}\text { Crude } \\
\text { OR }\end{array}$ & $95 \% \mathrm{CI}$ & $\begin{array}{l}\text { Adjusted } \\
\text { OR }\end{array}$ & $95 \% \mathrm{CI}$ & $\begin{array}{l}\text { Crude } \\
\text { OR }\end{array}$ & $(95 \% \mathrm{CI})$ & $\begin{array}{l}\text { Adjusted } \\
\text { OR }\end{array}$ & $95 \% \mathrm{CI}$ \\
\hline Hypertension & 65 & 3.1 & 32 & 9.6 & 371 & 1.8 & 1.87 & $1.43-2.46$ & 1.02 & $0.59-1.77$ & 1.39 & $0.79-2.43$ & 1.37 & $0.70-2.68$ \\
\hline Gestational diabetes & 612 & 28.7 & 103 & 14.3 & 3047 & 14.4 & 2.36 & $2.13-2.62$ & 1.62 & $1.35-1.95$ & 1.14 & $0.85-1.52$ & 1.05 & $0.78-1.42$ \\
\hline Breech birth & 62 & 2.9 & 12 & 1.7 & 527 & 2.5 & 1.17 & $0.90-1.53$ & 1.12 & $0.86-1.47$ & 3.19 & $1.39-7.32$ & 2.69 & $1.17-6.16$ \\
\hline Cesarean section & 571 & 26.7 & 173 & 24.0 & 3251 & 15.4 & 2.01 & $1.81-2.23$ & 1.56 & $1.31-1.86$ & 1.34 & $1.03-1.76$ & 1.31 & $0.99-1.74$ \\
\hline $\begin{array}{l}\text { Small for } \\
\text { gestational age }\end{array}$ & 100 & 4.7 & 46 & 6.4 & 779 & 3.7 & 1.29 & $1.04-1.60$ & 0.94 & $0.67-1.33$ & 0.75 & $0.46-1.24$ & 0.69 & $0.40-1.19$ \\
\hline $\begin{array}{l}\text { Large for } \\
\text { gestational age }\end{array}$ & 104 & 4.9 & 29 & 4.0 & 455 & 2.2 & 2.34 & $1.88-2.91$ & 1.77 & $1.18-2.67$ & 2.17 & $1.21-3.90$ & 2.28 & $1.25-4.17$ \\
\hline $\begin{array}{l}\text { Preterm birth } \\
32-36 \text { weeks }\end{array}$ & 155 & 7.3 & 47 & 6.5 & 794 & 3.8 & 2.00 & $1.67-2.39$ & 1.51 & $1.12-2.03$ & 0.97 & $0.62-1.53$ & 0.95 & $0.58-1.56$ \\
\hline $\begin{array}{l}\text { Very preterm birth } \\
<32 \text { weeks }\end{array}$ & 19 & 0.9 & 20 & 2.8 & 170 & 0.8 & 1.12 & $0.69-1.80$ & 0.39 & $0.17-0.90$ & 0.62 & $0.24-1.59$ & 0.58 & $0.22-1.53$ \\
\hline Shoulder dystocia ${ }^{a}$ & 9 & 0.4 & 1 & 0.1 & 52 & 0.3 & 1.71 & $0.84-3.48$ & 1.56 & $0.76-3.19$ & 0.95 & $0.10-9.31$ & NA & \\
\hline Stillbirth $^{\mathrm{a}}$ & 9 & 0.4 & 7 & 1.0 & 56 & 0.3 & 1.63 & $0.81-3.30$ & 0.41 & $0.12-1.39$ & 0.37 & $0.10-1.43$ & 0.37 & $0.08-1.74$ \\
\hline
\end{tabular}

Missing data on outcome excluded from analyses: hypertension 4.9\%, SGA, LGA, and cesarean section < $0.1 \%$ of pregnancies

$O R$, odds ratio; $C I$, confidence interval; Crude $O R$, adjusted for year of delivery; Adjusted $O R$, adjusted for year of delivery and covariates associated with exposure and outcome at $p<0.1$ as given in Supplementary Table 2

${ }^{a}$ Changes in adjusting variables due to small numbers. Shoulder dystocia: BMI and socioeconomic status categories reduced; stillbirth: BMI and socioeconomic status categories reduced 
We observed a nearly threefold increased risk of breech birth is women who purchased S-GAs in two or more trimesters compared with the F-GA group, but the risk was not increased when compared with that in the unexposed ones. This may be a chance finding, as the numbers were small and the confidence intervals wide. Fetal growth restriction has been identified as a predictive factor for breech presentation [31] while LGA has not [32].

Preterm birth was more common in S-GA users than in the unexposed group, and the risk was further increased, being $51 \%$ higher in women with continuous S-GA use. This finding is in contrast to a large Canadian study based on health administrative data [13]. While we adjusted for several covariates, including use of other psychiatric drugs and entitlement for special reimbursement for psychosis, we did not have data on maternal history of previous preterm births. It is also likely that maternal illness-related factors or illness severity may to some extent explain this result as the risk was not increased in comparisons between the S-GA and the F-GA groups. The lower risk of very preterm birth in S-GA users compared with the unexposed ones was an unexpected finding. This may be attributed to methodology as women giving birth in very early weeks were less likely to fulfill the criteria of purchases in at least two pregnancy trimesters.

Major strengths in our study include the comprehensive prospectively acquired data covering all births in the country during the study period. We adjusted for a high number of potential confounders obtained from the registers and included a comparison group of women using F-GAs during pregnancy, controlling to some extent for maternal illness. The prevalence of antipsychotic drug use and several of the examined outcomes in our study were comparable with those in other countries $[1,6,7,12]$, suggesting that the results are generalizable to other populations. Further, data in the drug prescription register is virtually complete [20] and as antipsychotics are reimbursed, it is likely that all purchases are included in our data. The MBR data have been validated and found to correspond well with medical records $[18,19]$. Due to the personal identification number awarded at birth or migration to all citizens, mothers, their drug purchases and children are reliably identified in the registers.

Use of register-based data has also limitations, as drug compliance cannot be confirmed. Women often discontinue drugs when they find out that they are pregnant and this applies also for antipsychotics [33]. However, we included analyses of women purchasing S-GAs in at least two trimesters, suggesting compliance. One limitation is that we have no information on the severity of maternal illness and the possibility of residual confounding by behavioral factors, such as alcohol and illicit drug use, which were not available in the register data. Yet, use of these substances strongly correlates with smoking included in our analyses.

\section{Conclusion}

Prenatal exposure to S-GAs is associated with an increased risk of pregnancy complications related to impaired glucose metabolism. Neonatal problems are common and occur similarly in S-GA and F-GA users.

Acknowledgments Open access funding provided by University of Helsinki including Helsinki University Central Hospital. The authors would like to acknowledge the Drugs and Pregnancy working group, THL, Kela, and FIMEA.

Authors' individual contributions Maria Ellfolk: conceptualization, methodology, writing-original draft preparation

Maarit K Leinonen: methodology, data curation, software, statistics, validation, writing, and editing

Mika Gissler: methodology, data curation, software, statistics, writing, and editing

Anna-Maria Lahesmaa-Korpinen: data curation, software, statistics

Leena Saastamoinen: conceptualization, methodology, writingoriginal draft preparation

Marja-Leena Nurminen: conceptualization, methodology, editing

Heli Malm: conceptualization, methodology, writing-original draft preparation, reviewing and editing, supervision

Funding information No funding has been granted for this study. The Drugs and Pregnancy project is financed by the Finnish Medicines Agency (FIMEA), the National Institute for Health and Welfare (THL), and the Social Insurance Institution in Finland (Kela).

\section{Compliance with ethical standards}

Conflict of interest The authors declare that they have no conflicts of interest.

Open Access This article is distributed under the terms of the Creative Commons Attribution 4.0 International License (http:// creativecommons.org/licenses/by/4.0/), which permits unrestricted use, distribution, and reproduction in any medium, provided you give appropriate credit to the original author(s) and the source, provide a link to the Creative Commons license, and indicate if changes were made.

\section{References}

1. Park Y, Huybrechts KF, Cohen JM, Bateman BT, Desai RJ, Patorno E, Mogun H, Cohen LS, Hernandez-Diaz S (2017) Antipsychotic medication use among publicly insured pregnant women in the United States. Psychiatr Serv 68(11):1112-1119. https://doi.org/ 10.1176/appi.ps.201600408

2. Tandon R (2014) Bridging the efficacy-effectiveness gap in the antipsychotic treatment of schizophrenia: back to the basics. J Clin Psychiatry 75(11):e1321-e1322. https://doi.org/10.4088/JCP. 14com09595

3. Henderson DC, Doraiswamy PM (2008) Prolactin-related and metabolic adverse effects of atypical antipsychotic agents. J Clin Psychiatry 69(Suppl 1):32-44

4. Hirsch L, Yang J, Bresee L, Jette N, Patten S, Pringsheim T (2017) Second-generation antipsychotics and metabolic side effects: a 
systematic review of population-based studies. Drug Saf 40(9): 771-781. https://doi.org/10.1007/s40264-017-0543-0

5. Boden R, Lundgren M, Brandt L, Reutfors J, Kieler H (2012) Antipsychotics during pregnancy: relation to fetal and maternal metabolic effects. Arch Gen Psychiatry 69(7):715-721. https:// doi.org/10.1001/archgenpsychiatry.2011.1870

6. Hatters Friedman S, Moller-Olsen C, Prakash C, North A (2016) Atypical antipsychotic use and outcomes in an urban maternal mental health service. Int J Psychiatry Med 51(6):521-533. https://doi. org/10.1177/0091217417696739

7. Reis M, Kallen B (2008) Maternal use of antipsychotics in early pregnancy and delivery outcome. J Clin Psychopharmacol 28(3): 279-288. https://doi.org/10.1097/JCP.0b013e318172b8d5

8. Newham JJ, Thomas SH, MacRitchie K, McElhatton PR, McAllister-Williams RH (2008) Birth weight of infants after maternal exposure to typical and atypical antipsychotics: prospective comparison study. Br J Psychiatry 192(5):333-337. https://doi.org/ 10.1192/bjp.bp.107.041541

9. Sadowski A, Todorow M, Yazdani Brojeni P, Koren G, Nulman I (2013) Pregnancy outcomes following maternal exposure to second-generation antipsychotics given with other psychotropic drugs: a cohort study. BMJ Open 3(7). https://doi.org/10.1136/ bmjopen-2013-003062

10. Bellet F, Beyens MN, Bernard N, Beghin D, Elefant E, Vial T (2015) Exposure to aripiprazole during embryogenesis: a prospective multicenter cohort study. Pharmacoepidemiol Drug Saf 24(4): 368-380. https://doi.org/10.1002/pds.3749

11. Lin HC, Chen IJ, Chen YH, Lee HC, Wu FJ (2010) Maternal schizophrenia and pregnancy outcome: does the use of antipsychotics make a difference? Schizophr Res 116(1):55-60. https:// doi.org/10.1016/j.schres.2009.10.011

12. Petersen I, Sammon CJ, McCrea RL, Osborn DPJ, Evans SJ, Cowen PJ, Nazareth I (2016) Risks associated with antipsychotic treatment in pregnancy: comparative cohort studies based on electronic health records. Schizophr Res 176(2-3):349-356. https://doi. org/10.1016/j.schres.2016.07.023

13. Vigod SN, Gomes T, Wilton AS, Taylor VH, Ray JG (2015) Antipsychotic drug use in pregnancy: high dimensional, propensity matched, population based cohort study. Bmj 350:h2298. https:// doi.org/10.1136/bmj.h2298

14. Sutter-Dallay AL, Bales M, Pambrun E, Glangeaud-Freudenthal NM, Wisner KL, Verdoux H (2015) Impact of prenatal exposure to psychotropic drugs on neonatal outcome in infants of mothers with serious psychiatric illnesses. J Clin Psychiatry 76(7):967-973. https://doi.org/10.4088/JCP.14m09070

15. Kulkarni J, Storch A, Baraniuk A, Gilbert H, Gavrilidis E, Worsley R (2015) Antipsychotic use in pregnancy. Expert Opin Pharmacother 16(9):1335-1345. https://doi.org/10.1517/ 14656566.2015.1041501

16. Lahesmaa-Korpinen A-M, Artama M, Gissler M, Heino A, Malm H, Ritvanen A (2014) Maternal medicine use and major congenital anomalies 1996-2010. 20/2014. National Instiutute of Health and Welfare (THL), http://urn.fi/URN:ISBN:978-952-302-199-0

17. THL (2019) Medical birth register - register description. In: ed. https://thl.fi/en/web/thlfi-en/statistics/information-on-statistics/ register-descriptions/newborns. Accesed 19 June 2019

18. Gissler M, Shelley J (2002) Quality of data on subsequent events in a routine Medical Birth Register. Med Iinform Internet Med 27(1): 33-38. https://doi.org/10.1080/14639230110119234

19. Teperi J (1993) Multi method approach to the assessment of data quality in the Finnish Medical Birth Registry. J Epidemiol Community Health 47(3):242-247

20. Fimea FMA, SII (2011) Finnish statistics of medicines 2010. http:// www.julkari.fi/handle/10024/130850

21. Sankilampi U, Hannila ML, Saari A, Gissler M, Dunkel L (2013) New population-based references for birth weight, length, and head circumference in singletons and twins from 23 to 43 gestation weeks. Ann Med 45(5-6):446-454. https://doi.org/10.3109/ 07853890.2013 .803739

22. Sorensen MJ, Kjaersgaard MI, Pedersen HS, Vestergaard M, Christensen J, Olsen J, Parner E, Pedersen LH, Bech BH (2015) Risk of fetal death after treatment with antipsychotic medications during pregnancy. PLoS One 10(7):e0132280. https://doi.org/10. 1371/journal.pone. 0132280

23. Huybrechts KF, Hernandez-Diaz S, Patorno E, Desai RJ, Mogun H, Dejene SZ, Cohen JM, Panchaud A, Cohen L, Bateman BT (2016) Antipsychotic use in pregnancy and the risk for congenital malformations. JAMA Psychiatry 73(9):938-946. https://doi.org/ 10.1001/jamapsychiatry.2016.1520

24. Cohen LS, Viguera AC, McInerney KA, Freeman MP, Sosinsky AZ, Moustafa D, Marfurt SP, Kwiatkowski MA, Murphy SK, Farrell AM, Chitayat D, Hernandez-Diaz S (2016) Reproductive safety of second-generation antipsychotics: current data from the Massachusetts General Hospital National Pregnancy Registry for atypical antipsychotics. Am J Psychiatry 173(3):263-270. https:// doi.org/10.1176/appi.ajp.2015.15040506

25. Frayne J, Nguyen T, Bennett K, Allen S, Hauck Y, Liira H (2017) The effects of gestational use of antidepressants and antipsychotics on neonatal outcomes for women with severe mental illness. Aust N Z J Obstet Gynaecol 57(5):526-532. https://doi.org/10.1111/ajo. 12621

26. Habermann F, Fritzsche J, Fuhlbruck F, Wacker E, Allignol A, Weber-Schoendorfer C, Meister R, Schaefer C (2013) Atypical antipsychotic drugs and pregnancy outcome: a prospective, cohort study. J Clin Psychopharmacol 33(4):453-462. https://doi.org/10. 1097/JCP.0b013e318295fe12

27. Freeman MP, Sosinsky AZ, Goez-Mogollon L, Savella GM, Moustafa D, Viguera AC, Cohen LS (2017) Gestational weight gain and pre-pregnancy body mass index associated with secondgeneration antipsychotic drug use during pregnancy. Psychosomatics. https://doi.org/10.1016/j.psym.2017.09.002

28. Panchaud A, Hernandez-Diaz S, Freeman MP, Viguera AC, MacDonald SC, Sosinsky AZ, Cohen LS (2017) Use of atypical antipsychotics in pregnancy and maternal gestational diabetes. J Psychiatr Res 95:84-90. https://doi.org/10.1016/j.jpsychires.2017. 07.025

29. Chen J, Huang XF, Shao R, Chen C, Deng C (2017) Molecular mechanisms of antipsychotic drug-induced diabetes. Front Neurosci 11:643. https://doi.org/10.3389/fnins.2017.00643

30. Newport DJ, Calamaras MR, DeVane CL, Donovan J, Beach AJ, Winn S, Knight BT, Gibson BB, Viguera AC, Owens MJ, Nemeroff CB, Stowe ZN (2007) Atypical antipsychotic administration during late pregnancy: placental passage and obstetrical outcomes. Am J Psychiatry 164(8):1214-1220. https://doi.org/10.1176/appi.ajp. 2007.06111886

31. Cammu H, Dony N, Martens G, Colman R (2014) Common determinants of breech presentation at birth in singletons: a populationbased study. Eur J Obstet Gynecol Reprod Biol 177:106-109. https://doi.org/10.1016/j.ejogrb.2014.04.008

32. Macharey G (2018) Breech presentation and delivery in singleton term pregnancies in Finland. In: Obstetrics and Gynecology ed. Helsinki University

33. Margulis AV, Kang EM, Hammad TA (2014) Patterns of prescription of antidepressants and antipsychotics across and within pregnancies in a population-based UK cohort. Matern Child Health J 18(7):1742-1752. https://doi.org/10.1007/s10995-013-1419-2

Publisher's note Springer Nature remains neutral with regard to jurisdictional claims in published maps and institutional affiliations. 